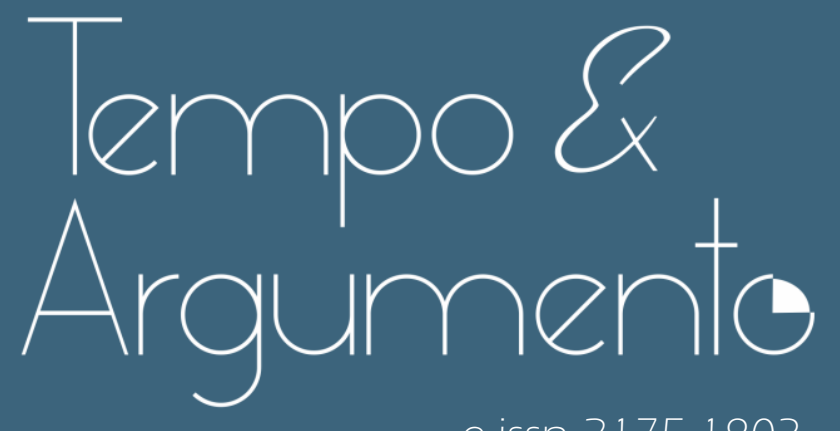

e-issn 2175-1803

\title{
Travesti: textos-vestígios na construção de uma identidade - Jornal Lampião da Esquina (1978-1981)
}

- Ronaldo Pires Canabarro

Doutorando em História, Política e Bens Culturais pela Fundação Getúlio

Vargas (FGV). Técnico em Assuntos Educacionais na Universidade

Federal do Rio de Janeiro (UFRJ).

Rio de Janeiro, RJ - BRASIL

lattes.cnpq.br/4203210611722519

ronaldcanabarro@gmail.com

(D) orcid.org/0000-0002-3548-3968

- Marlise Regina Meyrer

Doutora em História pela Pontifícia Universidade Católica do Rio Grande do Sul (PUCRS). Professora do Programa de Pós-Graduação em História (PPGH) da Pontifícia Universidade Católica do Rio Grande do Sul (PUCRS).

Porto Alegre, RS - BRASIL

lattes.cnpq.br/8160991187326250

meyrer_nh@hotmail.com

(iD)

orcid.org/0000-0002-6446-7799

Para citar este artigo:

CANABARRO, Ronaldo Pires; MEYRER, Marlise Regina. Travesti: textos-vestígios na construção de uma identidade - Jornal Lampião da Esquina (1978-1981).

Tempo e Argumento, Florianópolis, v. 12, n. 29, e0 106, jan./abr. 2020.

do) http://dx.doi.org/10.5965/2175180312292020e0106

Recebido: 30/08/2019

Aprovado: 04/02/2020 


\title{
Travesti: textos-vestígios na construção de uma identidade - Jornal Lampião da Esquina (1978-1981)
}

\begin{abstract}
Resumo
A pesquisa analisa as construções discursivas da imagem de travestis, no jornal Lampião da Esquina (1978-1981). O estudo traz aspectos que colaboram para ampliar o entendimento de como a identidade das travestis foi se construindo enquanto identidade política, durante as décadas de 70 e 80 . Ainda, contribui para o entendimento de como as identidades de lésbicas, gueis/gays, bissexuais, travestis e transexuais se afirmaram e se constituíram como força política no Brasil. A partir da metodologia da análise de conteúdo, buscamos identificar o gênero sócio gramatical a que se referem os autores do jornal sobre travestis, percebendo como o uso comum dos condicionantes gramaticais masculinos ou femininos contribuiu para a afirmação/criação das identidades travestis. Da mesma forma, identificamos uma polaridade conflituosa nos discursos do jornal entre as expressões fazer e ser travesti.
\end{abstract}

Palavras-chave: Travesti. Identidade. Gênero. Lampião da Esquina. Imprensa.

\section{Travesti: texts-vestiges in the construction of an identity - Lampião da Esquina Newspaper (1978-1981)}

\begin{abstract}
The research analyses the discursive constructions of the image of travestis, in the Lampião da Esquina newspaper (1978-1981). The study brings together aspects that help to expand the understanding of how the travestis identity was constructed as a political identity during the 1970s and 1980s. It also contributes to the understanding of how lesbian, gay, bisexual, travestis and transsexuals were affirming themselves and becoming a political force in Brazil. With the methodology of content analysis, we seek to identify the socio-grammatical gender on which the newspaper authors refer to travestis, perceiving how the common use of the masculine or feminine grammatical determinants contributed to the affirmation / creation of travesti identity. In the same way, we identified a conflicting polarity in the newspaper speeches among the expressions "to do" travesti and "to be" travesti.
\end{abstract}

Keywords: Transvestite. Identity. Gender. Lampião da Esquina. Press. 
O artigo estuda o processo de produção, circulação e apropriação das identidades travestis na imprensa alternativa, especificamente, no jornal Lampião da Esquina. O periódico circulou, principalmente, entre São Paulo e Rio de Janeiro, alcançando todo o Brasil por meio de assinaturas individuais, de abril de 1978 a julho de 1981. Ao todo, foram publicadas 41 edições (38 regulares e três edições extras).

A identidade denominada "travesti" tem se construído de forma ambígua, uma vez que não aciona o discurso de "homem" e, embora seja feita de elementos femininos, nem sempre advoga o desejo de ser, identitariamente, “mulher" (BENEDETTI, 2005; BÖER, 2003; CARDOZO, 2010). Nos discursos construídos sobre, das e, também, elaborados por algumas das travestis, não raro encontramos a perspectiva de uma não-conformação com as regras definidoras de corpos, desejos, identidades e expressões de gênero encontradas em nossa sociedade (BENEDETTI, 2005; LANZ, 2015; SILVA, 2007). Como um terceiro gênero, travestis, segundo propomos, podem ser descritas como identidades transviadas. O uso do termo transviado é também uma possibilidade aventada por Berenice Bento na apresentação do livro de Larissa Pelúcio, Abjeção e desejo: uma etnografia travesti sobre o modelo preventivo de aids (2009). Bento (2009, p. 17) afirma que as contribuições de Pelúcio são criativas e singulares para os estudos "queer brasileiros", ou "estudos transviados", como prefere "nomear este novo campo de pesquisa”.

Embora não seja o primeiro jornal brasileiro destinado a e/ou feito por homossexuais, o Lampião da Esquina alcançou maior capilaridade, repercussão, duração, periodicidade e organicidade, entre o final da década de 1970 e o início dos anos 1980, período em que grupos organizados de gueis e lésbicas se fortaleciam, e o Movimento Homossexual Brasileiro $(\mathrm{MHB})^{2}$ começava a surgir (FACCHINI, 2005; MACRAE, 2018; RODRIGUES, 2012). Rogério Bastos Cadengue

\footnotetext{
"Utilizamos o anglicismo "gay" quando não nos cabe a escolha ou para respeitar referências; ademais, optamos pela grafia em português (guei), confirmada pelo sistema de busca online do Vocabulário Ortográfico da Língua Portuguesa - VOLP (2015), mantido pela Academia Brasileira de Letras. Além disso, o jornal usa a palavra grafada nesse formato como uma escolha, provavelmente, orientada contra os estrangeirismos.

${ }^{2}$ Como exemplo, podemos citar o Somos, grupo criado em 1978 (logo após o início da circulação do Lampião), pioneiro em se registrar como entidade de defesa dos direitos de pessoas homossexuais, e o Grupo Gay da Bahia (GGB), criado em 1980, ainda em funcionamento.
} 
(1980) menciona a produção dos jornais por e para homossexuais como um elemento alternativo, já que recebiam um tratamento inadequado por parte dos veículos de comunicação de massa, sendo utilizados para a produção de "manchetes espalhafatosas".

Seu período de circulação coincide com o momento em que a repressão sobre os meios de comunicação começava a se abrandar em relação à década anterior, marcada pela forte censura promovida pelos governos militares. No final da década de 1970 e começo de 1980, tem início a denominada "abertura democrática" e o lento enfraquecimento do autoritarismo, iniciado em 1964. Nesse contexto, a imprensa alternativa emergia como uma possibilidade jornalística de cunho político, ativista, pela "intransigência cultural, e em certa medida moral, pela afinidade com os motivos ideológicos que moviam ativistas políticos" (KUCINSKI, 2003, p. 36).

O Lampião da Esquina surge nesse contexto. Seu primeiro número (o número zero), publicado em abril de 1978, foi elaborado por intelectuais e jornalistas que tinham como objetivo principal "sair do gueto". O ato era visto não somente como um "assumir-se", mas, para além de uma identidade pessoal, colocar-se na rua, dar visibilidade às várias causas. O jornal almejava mostrar as várias nuances das homossexualidades, a diversidade desse grupo e suas especificidades, suas gírias e sua história, como uma forma de lutar contra o estigma de ser homossexual:

[...] é preciso dizer não ao gueto e, em consequência, sair dele. O que nos interessa é destruir a imagem-padrão que se faz do homossexual, segundo a qual ele é um ser que vive nas sombras, que prefere a noite, que encara a sua preferência sexual corno uma espécie de maldição, que dá aos ademanes e que sempre esbarra, em qualquer tentativa de se realizar mais amplamente enquanto ser humano, neste fator capital: seu sexo não é aquele que desejaria ter. (SAINDO, 1978, p.02)

Apesar do processo de abertura democrática em marcha, o Lampião da Esquina não escapou da vigilância sobre o que produzia. Na reportagem de capa do número zero, Celso Curi deixa clara a situação de repressão e censura por parte do governo militar sobre os homossexuais. O jornalista estava sendo processado por "atentado à moral e aos bons costumes" e por fazer apologia ao 
homossexualismo (sic). Devido a uma seção, publicada durante dois anos, denominada "Coluna do Meio", Cury teve de responder ao processo-crime. As acusações e o trâmite legal duraram tempo suficiente para que fosse demitido, "por contenção de gastos", do Jornal Última Hora, onde publicava essa coluna. Cury foi absolvido ao fim do processo, que durou de 1976 a 1979.

No início de 1979, os editores do jornal foram intimados pela polícia para depor. Havia a denúncia de que o jornal estava praticando atos contra "a moral e os bons costumes". Ao destacar a intimação, os lampiônicos (apelido usado desde o início para se autodesignarem) se posicionaram firmemente, criticando o trabalho policial. Apesar da ensaiada abertura democrática, ainda vigorava a tática de intimidar a imprensa que "não estava vinculada direta ou indiretamente aos meios ou às ideias oficiais" (PENTEADO, 1979, p. 06). Não havia um processo formado quando foram chamados a depor, apenas um inquérito policial baseado em denúncia. As perguntas, segundo os lampiônicos, procuravam por algo de “imoral” na publicação; no entanto, para os autores, não havia nada que fosse ou parecesse imoral, "a menos que se considere imoralidade defender a ecologia, tentar conscientizar homossexuais do seu papel atuante na sociedade ou reconhecer os direitos das mulheres e dos índios" (PENTEADO, 1979, p. 06).

O Lampião da Esquina costumava lidar com a subversão "das palavras e das coisas". Desde o início, seu editorial fez escolhas semântico-políticas interessantes, como o uso da palavra "guei" em vez de "gay". O uso da palavra "bicha" é outra disputa que ocorre dentro do jornal. Alguns jornalistas, em especial Aguinaldo Silva, usam e defendem essa definição. A linguagem é um meio de definição das identidades, é através dela que nos referimos uns aos outros. É por meio da linguagem que os conceitos sobre o que se é ou se pode ser está definido; mas ela não é estanque, nem estática: é fluida e constante. Quando nomeamos algo, também o (re)criamos. Não há uma única via nesse caminho. Aquilo que é nomeado é também definido e definidor. Ao nomear, interage-se dentro de uma lógica que retorna e se refaz. Não é um poder que nomeia simplesmente, como num ato divino, nem significa que essa "coisa" não exista de alguma forma antes de ser nomeada. Mais do que isso, é um ir e vir de palavras e coisas que se (con)fundem: 
[...] parece que é em virtude do poder do sujeito ou de sua vontade que um fenômeno é trazido, ao nomeá-lo, à existência. Numa reformulação crítica do performativo, Derrida deixa claro que esse poder não é a função de uma vontade originadora, mas é sempre derivativo. (BUTLER, 2000, p. 121)

O uso e as escolhas das/pelas palavras poderiam auxiliar na afirmação de seus posicionamentos, o que era considerado, por alguns dos editores, como um ato político e performativo. Aguinaldo Silva publicou um artigo intitulado "As palavras, para que temê-las?" (SILVA, 1978, p. 5) em que comenta que algumas pessoas escreviam para o jornal reclamando que o uso frequente de palavras como bicha ou boneca, usadas rotineiramente, seriam ofensas e causariam espanto, não combinando com aquele meio de comunicação. O autor decide se posicionar, uma vez que o uso daquelas palavras era intencional e politicamente estratégico. Sua intenção era resgatá-las do vocabulário machista e esvaziá-las do sentido pejorativo, de modo que não era preciso criar outro vocabulário para se autodenominar, como "entendidos", ou usar palavras estrangeiras, como "gay". O sujeito se empodera ao usar as palavras que comumente o referem, sem medo do "peso" que carregam. Para Aguinaldo Silva, se alguém o chamasse de bicha, responderia que era muito mais: era uma "tricha" (SILVA, 1978, p. 5).

Ainda segundo o jornal, a ideia de publicar um periódico na chamada imprensa alternativa surgira meses antes, suscitando várias reuniões nas quais se definiu o projeto de criar um veículo de imprensa que pautasse aquilo que o restante dos meios de comunicação considerava não prioritário. Onze pessoas assumiram, portanto, o compromisso histórico de fazer nascer o Lampião da Esquina. Além disso, os conselheiros não seriam responsáveis apenas pela linha editorial do jornal, mas também pela escolha e viabilização da publicação de Livros da recém-criada Editora Lampião (que, a partir do número 1, passou a se chamar Da Esquina - Editora). Os autores são apresentados na primeira edição (SENHORES, 1978, p. 2): Adão Costa - Jornalista; Aguinaldo Silva - Jornalista e escritor; Antônio Chrysóstomo - Jornalista; Clóvis Marques - Jornalista; Darcy Penteado - Artista plástico e escritor; Francisco Bittencourt - Poeta, crítico de arte e jornalista; Gasparino Damata - Jornalista e escritor; Jean-Claude Bernardet - Crítico de cinema, um dos teóricos do Cinema Novo; João Antônio 
Mascarenhas - Advogado, jornalista e tradutor; João Silvério Trevisan - Cineasta e escritor; Peter Fry - Antropólogo.

O surgimento de O Lampião da Esquina ocorreu não só no embalo do processo de abertura política, mas também num período em que o surgimento de movimentos sociais para os direitos de homossexuais estava com "condições amadurecidas" (GREEN, 2000). Inicialmente, denominou-se "Movimento Homossexual Brasileiro - MHB". A identidade lésbica foi inserida a partir de 1993, nos Encontros realizados pelo Movimento. O termo homossexual foi alterado para "gays e lésbicas" como parte da sigla, no Encontro de 1995. Somente em 1997, se insere o termo "travestis" e, finalmente, no Encontro de 2005, os termos “bissexuais e transexuais” (SIMÕES; FACCHINI, 2009). Todavia, é só em 2008, por decisão tomada na "I Conferência Nacional de Gays, Lésbicas, Bissexuais, Travestis e Transexuais", que se passou a denominar movimento LGBT Lésbicas, Gays, Bissexuais, Travestis e Transexuais; a identidade lésbica à frente da sigla foi uma reivindicação do movimento de mulheres lésbicas, com o intuito de dar maior visibilidade à sua identidade dentro do próprio movimento (FACCHINI, 2005).

James Naylor Green (2000) descreve a gestação daquilo que viria a se chamar "SOMOS", como tendo início entre o verão de 1978 e o princípio de 1979, com reuniões em apartamentos na cidade de São Paulo, nas quais algumas pessoas (na maioria homens homossexuais, segundo o autor) se reuniam com o intuito de estudar, debater e pensar alternativas para a violência contra homossexuais. Liam o Lampião da Esquina como forma de fortalecer seus debates e, muitas vezes, se indignavam com o que os outros jornais publicavam sobre a homossexualidade. O debate ocorrido no Departamento de Ciências Sociais da Universidade de São Paulo, em fevereiro de 1979 (quando o nome somos foi definido), é considerado, por Green (2000, p. 274), como parte das discussões sobre a organização das "minorias" brasileiras, integrando mulheres, negros, indígenas e homossexuais; de igual modo, o evento serviu para que o “movimento de gays e lésbicas do Brasil 'se assumisse”. A reportagem intitulada "Grupo SOMOS: uma experiência" destacou: "nos últimos três anos, surgiram inúmeras tentativas de tomar posição. Uma delas é a experiência do Somos, cuja 
história coincide com a própria existência de Lampião" (GRUPO, 1979, p. 2) - um indicativo do quanto o jornal, de certa forma, estava imbricado nos primórdios do movimento homossexual.

Em termos metodológicos, a pesquisa investigou todas as edições do Lampião da Esquina. O corpo de textos selecionado somou 760 páginas, que foram lidas, catalogadas e analisadas. Foram identificadas e tabeladas todas as referências às palavras "travesti" e "travestis" nos textos do jornal, bem como assinaladas a denotação do gênero masculino ou feminino referente aos termos. Após essa leitura inicial, foi possível identificar variantes que pudessem estabelecer um caminho para a pesquisa.

Destacamos algumas opções teórico-metodológicas, como a adoção do termo "travestilidade", em contraposição ao uso das ciências psi (psiquiatria, psicanálise e psicologia) de "travestismo". Em especial, porque alguns pesquisadores (CARDOZO, 2009; DUQUE, 2009; LIMA, 2009; NOGUEIRA, 2009; PATRÍCIO, 2008; PELÚCIO, 2005) questionam o uso do sufixo ismo, com raiz patológica, referente a transtorno e distúrbio, e propõem o sufixo dade, que considera sua construção social e diferentes modos de ser/existir (AMARAL; et al., 2014). Igualmente, sublinhamos o uso do termo textos-vestigios, uma proposta de Andréia Cristina Lopes Frazão da Silva (2012) para substituir o termo fontes, pois textos-vestigios expressa o sentido de restos e coisas que remanescem, palimpsestos, o que é mais condizente com o fato de que o passado não está totalmente preservado (SILVA, 2012).

Da mesma forma, optou-se pelo uso de pronomes no gênero feminino para travestis. Essa postura foi adotada com base, por um lado, em autores/as que trabalham sobre o tema (BENTO, 2008; DUQUE, 2009; PELÚCIO, 2005 , entre outros), e por outro e mais importante, nas discussões e reivindicações dos movimentos sociais de travestis e transexuais e, em certa medida, nas dos movimentos LGBTs. O artigo feminino para se referir às travestis é uma decisão política importante, pois o gênero em que elas se apresentam socialmente é o feminino, independente da genitália biológica. Apenas utilizamos pronomes e artigos masculinos em referência às travestis quando estivermos respeitando o ponto de vista dos textos-vestígios utilizados no estudo. 
Para melhor entendimento da temática, acionamos definições enunciadas pelos discursos que historicamente determinaram essa(s) identidade(s), tais como o médico/psiquiátrico, o psicológico, o jurídico, além dos discursos das Ciências Sociais e do próprio movimento social. Entretanto, as descrições conceituais não são inscritas como definidoras e/ou limitantes da vivência individual de uso do seu sexo/desejo/identidade. Entendemos que há uma pluralidade discursiva e de sentidos atribuídos a cada uma dessas definições. Por exemplo, algumas travestis demandam a mudança de identidade civil, ou, ao menos, querem ser chamadas pelo nome que escolheram, fazendo uso do nome social, mas não são todas as travestis que apresentam o mesmo discurso. A tentativa de descrevê-las tem o intuito de nortear esse texto e não de classificálas, porque, certamente, a todas as classificações escapam as pluralidades das identidades. Além disso, existem relações de tempo/espaço que configuram os sentidos dados a essas identidades. Dessa maneira, concordamos com Benedetti (2005):

As múltiplas diferenças e particularidades vivenciadas pelas pessoas nesse universo social não podem ser reduzidas a categorias ou classificações unificadoras, pois estas, ao tornar equivalentes visões de mundo e identidades às vezes até antagônicas, podem ser arbitrárias. (BENEDETTI, 2005, p. 17)

Em sua tese de doutorado, Leite Júnior (2008) apresenta uma análise dos termos "travesti" e "transexual" conforme construídos e apresentados pela ciência médica, em especial, pelas áreas psi. O autor descreve a história do termo:

Segundo o autor [refere-se à Hirschfeld (1991)], "travesti" (transvestiten) vem dos termos em latim trans que significa através e vestitus, com o sentido de estar vestido, e travestismo (transvestism) de trans e vestis, igual a roupa. O Dicionário Houaiss da Língua Portuguesa data a palavra travesti como originária do francês e tendo sua primeira aparição registrada em 1543, significando disfarçado, derivada de travestire (1512), ou seja, disfarçar-se. (LEITE JUNIOR, 2008, p. 102, grifos do autor).

Lynne Friedli [...] afirma que o termo travesti foi usado na Inglaterra em 1652 para designar mulheres que se vestiam como homens. (FRIEDLI, 1999, apud LEITE JUNIOR, 2008, p. 102, grifos do autor).

Já para Terry Castle, este passa a ser um termo comum neste país (Inglaterra) durante o lluminismo, criando nos bailes de máscaras uma verdadeira cultura do travesti. (CASTLE, 1999 apud LEITE JUNIOR, 2008, p. 102, grifos do autor). 
Essa definição reconhece o termo "travestismo", descrevendo-o como uma patologia, como um exemplo de processo de patologização. Mesmo assim, é importante destacar que ele já apresenta uma separação entre o desejo sexual orientado a um gênero (heterossexual, homossexual, bissexual) e a expressão de gênero adotada pelo indivíduo (LEITE JÚNIOR, 2008). Hirschfeld (1991) apud Leite Junior (2008) discorre sobre as possibilidades de combinações que as pessoas poderiam ter com relação à sua sexualidade, indo dos casos em que homens procuram mulheres masculinas, o que seria um caso de homossexualidade, até aqueles em que as alterações para homossexualidade ou bissexualidade se manifestavam somente nos gostos e gestos, como homens sensíveis, mulheres agressivas, até ao uso de roupas - nesse caso, estariam incluídas as travestis; o médico e psicólogo alemão chegou a um cálculo de 43.046 .721 combinações possíveis (LEITE JÚNIOR, 2008). O autor complementa:

[...] vemos desta forma o nascimento de uma nova categoria clínica e uma personagem, mesmo que não intencionalmente, patologizada: o travestismo e o indivíduo travesti, através da autonomização da questão da troca de vestuário entre os sexos, mas não mais ligado necessariamente à homossexualidade, ao hermafroditismo psíquico ou a alguma forma de paranoia. (LEITE JÚNIOR, 2008, p. 105)

A Sexologia e as ciências psi puderam, no século XIX, discorrer sobre a possibilidade de disputar os discursos sobre o "verdadeiro sexo" de alguém - a problematização e "separação" entre sexo e gênero só será realizada em meados do século XX. No decorrer dos anos, com os estudos sobre as patologias mentais, a American Psychiatric Association (APA) reuniu em uma publicação todas as doenças, disforias e transtornos mentais, para, de alguma forma, catalogá-los e enumerá-los em códigos. Nasce o Diagnostic and Statistical Manual of Mental Disorders (DSM), com a primeira edição em 1952 e que, atualmente, se encontra na quinta versão revisada e ampliada (APA, 2014). Durante esse período, muitas patologias foram incluídas, outras retiradas, como a homossexualidade, que deixou o manual em 1973, por conta da pressão militante do movimento Gay estadunidense, nascido em 1969. No Brasil, a despatologização da homossexualidade se deu na década de 1980. No entanto, apenas em 1992, a 
Organização Mundial da Saúde (OMS) oficialmente excluiu a homossexualidade do rol de doenças mentais no CID (Código Internacional de Doenças), adotado como referência nos diagnósticos médicos em praticamente todos os países (BELMONTE, 2009).

No DSM, a travestilidade é apresentada junto aos transtornos da identidade sexual, incluindo o travestismo ambivalente. Tais transtornos descrevem pessoas que, ao nascerem, recebem a designação masculina por possuírem um pênis, mas que desejam utilizar, por um período da sua vida, uma roupa ou um acessório feminino para fins de satisfação da libido e do desejo sexual. Dessa forma, conforme o manual, travesti é alguém que num momento apresenta-se como mulher e, noutro, como homem. No entanto, é preciso destacar que a categoria travesti sobrepõe-se à categoria transexual, pois esta última é recente e ainda tem uma pequena repercussão no universo apresentado (BENEDETTI, 2005). O autor auxilia a pensar sobre outras singularidades:

[...] o feminino travesti não é o feminino das mulheres, é um feminino que não abdica de características masculinas, porque se constitui num constante fluir entre esses polos, quase como se cada contexto ou situação pronunciasse uma mistura específica dos ingredientes de gênero. (BENEDETTI, 2005, p. 96).

A partir da primeira Conferência Nacional de Gays, Lésbicas, Bissexuais, Travestis e Transexuais - GLBT (2008), entendeu-se que muitas travestis modificam seus corpos por meio de hormonioterapias, aplicações de silicone e/ou cirurgias plásticas, mas que isso não é regra para todas. Não raro, a definição de travestilidade leva em consideração que, diferentemente das transexuais, as travestis não desejariam, não poderiam ou não precisariam realizar a cirurgia de redesignação sexual. No entanto, procedimentos cirúrgicos relacionados às genitálias também não são regra entre pessoas transexuais (BENTO, 2008). Em meio a esse contexto, o gênero pode ser entendido como uma identidade descolada da, ou não ligada diretamente à genitália de nascimento. Mas essa cisão não é estanque e possível de ser vivenciada de fato, pois os discursos sobre sexo e gênero se confundem, se fundem, se comprimem, se estimulam, se complementam, se separam, se deslocam e se criam nas relações sociais e temporais - ou seja, tornam-se os “dispositivos históricos” de Foucault (2006). 
Para Judith Butler (2000), os discursos sobre sexo/gênero vinculam-se entre a materialidade do sexo e a performatividade do gênero, mas essa separação é contraditória, posto que sexo é, desde sempre, discursivo e normativo; é aquilo que Michel Foucault chamou de "ideal regulatório" (BUTLER, 2000, p. 153). A autora questiona o sexo como algo natural, um dado biológico pronto e verdadeiro, como um construto idealizado que é materializado ao longo do tempo. O sexo não é algo pronto sobre o qual construímos corpos, identidades, desejos, mas é também um construto social, histórico e geograficamente localizado (LAQUEUR, 2001). Fazendo questionamentos sobre o sujeito que constrói o gênero, e se é um "eu” ou um “hós” que o faz, Butler (2000) traz à tona os limites discursivos dessa possibilidade de encarar o sexo e o corpo como dados naturais, pois o corpo não é, mas está. Está construído e funcionando como uma matriz de sexo e de gênero.

\section{"O" travesti ou "A" travesti? O Lampião da Esquina e a gramática das identidades}

A escolha dos textos-vestígios utilizados na presente pesquisa levou em consideração fatores relevantes para sua construção, tais como o contexto político-ideológico, o período histórico, a perspectiva editorial e a subjetividade dos discursos e conteúdos produzidos. Ademais, o recorte temático escolhido, ou seja, as identidades travestis, levou também em consideração os contextos de subjetividades político-sexuais.

A análise de conteúdo de Lawrence Bardin (1977) permitiu a exploração do material utilizado como texto-vestígio. Após uma leitura flutuante, também denominada pré-análise (BARDIN, 1977, p. 96), selecionamos enunciados, trechos e palavras (temas) que fariam parte da análise, com o propósito de responder à pergunta: o que o Lampião da Esquina escreveu sobre travesti?

A palavra "travesti", etimologicamente, é um substantivo de ambos os gêneros, masculino e feminino (HOUAISS, 2008). Segundo a regra, usa-se "o" ao se referir a um homem travesti e "a" para referir uma mulher travesti. A regra não estabelece o que define um homem ou uma mulher, então fica a cargo da lente discursiva de quem os/as nomeia: se a genitália define o artigo, trata-se da 
herança essencialista do discurso biomédico produtor de machos e fêmeas, por exemplo. Isso desconsidera que homens e mulheres constroem seus corpos para além de genitálias, naturalizando uma apropriação construtiva do sexo e do gênero. Atualmente, há certo consenso entre pesquisadores/as sobre a referência no gênero feminino às pessoas cujas identidades se autodenominam travesti (BENEDETTI, 2005; DUQUE, 2013; KULICK, 2008). Falar/escrever "a" travesti é uma forma de percebê-la a partir de sua "performance de gênero" (BUTLER, 2016).

O gênero das travestis, no jornal, é apresentado como ambíguo e seu espaço no mundo é também discutido. Até esse período, para fins de construção de si mesmas, as travestis partem do mundo homossexual. As tensões sobre o que a travesti representa dentro da "classe das bichas" é uma constante dúvida.

Um exemplo é o artigo "Tigres de Papel", do lampiônico João Antônio Mascarenhas, respondendo à crítica de um leitor que afirmava que os editores do jornal, em especial o próprio Mascarenhas, desprezavam as "bichas afetadas e os travestis" (MASCARENHAS, 1978, p. 9). Ao formular sua resposta, Mascarenhas argumenta que a efeminação das bichas seria uma forma de manutenção do machismo, uma vez que estereotipava a conduta de um homem, já que, para ele, a efeminação era artificial e forçada. Segundo Mascarenhas, "os travestis, então, levam essa atitude ao paroxismo", chegando a fazer incisões cirúrgicas, tomar hormônios e buscar incessantemente a imagem da "mulher vamp", vendida por Hollywood nos anos 1920 e 1930. O autor reforça que não discrimina nem deseja uma cisão entre a "população homossexual", todavia mantém seus argumentos, sustentando que as "bichas afetadas e os travestis" introjetaram essa máxima machista e a reproduziam de forma inconsciente (MASCARENHAS, 1978, p. 9).

Nas páginas do jornal, observamos o enquadramento da travesti em algum conceito/lugar e o frequente reforço de construção da identidade homossexual pela forma binária de entendimento, para a qual definir uma identidade envolve a exclusão de outra. Há uma reprodução adaptada de um artigo publicado originalmente na revista norte americana Christopher Street, escrito por Seymour Kleinberg, que discute sobre o "gay macho", apresentando 
aspectos da identidade ultra masculinizada de muitos gays norte-americanos, cujo discurso desprezava a feminilidade. O autor comenta sobre a feminidade exacerbada das bichas no Brasil,

Por isto é que as feministas censuram travestis e bonecas que ainda tentam ostentar os escravizantes emblemas do passado. Esta censura seria válida se fosse sincera a imitação dos travestis. Mas estes não têm a ilusão de que são mulheres: só com os que já beiram a loucura isto acontece. Os demais têm um compromisso com a ambiguidade: não são nem homens nem mulheres, e raramente andróginos; a essência de seu comportamento é neutra. (GAY-MACHO, 1979, p. 8)

No texto, "travestis", as que não se reivindicam mulheres, são diferenciadas das "loucas", possivelmente as transexuais, que eram vistas como portadoras de um transtorno psiquiátrico. Há também, segundo o texto, um “compromisso com a ambiguidade", o que coloca as travestis nesse entre-lugar, num local que não é homem nem mulher, mas é um ambíguo.

Um bom exemplo é a história de Verushka, estampada da capa do Lampião da Esquina na edição n. 10, de 1979. A reportagem conta que Verushka estava sendo perseguida pelo síndico que desejava que ela usasse gravata e paletó, deixando claro que o elevador social não poderia ser usado por pessoas cujos trajes não estivessem em conformidade com "a moral e os bons costumes". O texto foi conduzido pelo jornalista de forma ambígua. Apresenta-se o nome, possivelmente de registro, Vicente de Fluri, destacando, ao lado, a definição "o travesti Verushka”, que tinha a ver com sua profissão de artista que fazia shows em casas noturnas. Durante o dia, segundo o jornal, Verushka se vestia com roupas "normais", pois era "maquiador e trabalhava num salão de beleza" (SILVA, 1979, p. 3). No entanto, a fotografia publicada na reportagem mostra Verushka em sua atividade de cabeleireira com roupas e acessórios definidos pela sociedade como femininos, embora a legenda contradiga a evidência da imagem: "a mulher-maravilha só se veste daquela forma nos shows". (SILVA, 1979, p. 3)

Em uma crônica intitulada "O travesti, esse desconhecido", Darcy Penteado escreve sobre o papel "do travesti na emancipação feminina" (PENTEADO, 1980, p. 3). O autor argumenta que "o travesti" deseja somente ser mulher-objeto e que, portanto, num futuro próximo, no qual as mulheres estariam livres das 
amarras do machismo e do sistema patriarcal, a parte da sociedade que sentisse saudades da época dos machões se serviria das travestis para o ato sexual e o seu uso como mulher-objeto. Nesse espaço, mais uma vez, é possível observar um discurso que reforça a imagem das travestis como pessoas inferiores.

Penteado vê nas travestis um agir "inconsciente" a favor do machismo e um querer parecer mulher e não aceitar sua condição masculina. Em outro artigo (PENTEADO, 1980, p. 16), o mesmo autor, ao apresentar o espetáculo "A Louca da Consolação", reflete sobre a definição de travestis, dizendo que essa tarefa teria sido muito bem interpretada pelo ator, autor e roteirista da peça, Marcos Bragato. Segundo Penteado, Bragato "não define tudo, mas acrescenta elementos úteis para a pesquisa dessa marginalidade (?) social, sem dúvida a mais anticonformista e mais fora dos padrões convencionais (?) da sociedade atual" (PENTEADO, 1980, p. 16).

O autor faz uso da dúvida para fazer refletir sobre as afirmações referentes à identidade travesti no que se refere à marginalidade, mas sua forma de organização do texto coloca em xeque essas afirmações ao fazer uso do ponto de interrogação, seja para questionar os padrões convencionais, ou mesmo para confrontar a ideia de que a travesti não questiona os padrões, mas os reifica no sistema machista, como argumentado em número anterior. Penteado ainda assinala que a peça usa a "ação afrescalhada" e "euforicamente exteriorizada" das travestis para conseguir transmitir a intenção do texto. Sobre o tema da peça (a travestilidade), Penteado afirma: "existe muito, senão tudo a pesquisar" (PENTEADO, 1980, p. 16).

Talvez a edição mais significativa para a temática tenha sido a que trouxe na capa o título: Brasil, Campeão Mundial de Travestis, na edição n. 32, de janeiro de 1981. Destaca-se o uso de condicionantes gramaticais do gênero feminino para se referir às travestis, mas usado apenas quando ligado ao nome próprio ou a outros termos como "boneca" ou "bicha-biônica". Além da denotação no feminino, as travestis não são tratadas com ironia nessa edição. Embora a linguagem adotada continue utilizando condicionantes gramaticais no masculino, é possível notar uma afirmação da feminilidade das travestis ao longo do texto. A capa é ilustrada com uma fotografia de 11 travestis com indumentária e pose 
tradicional de um time de futebol. Abaixo da fotografia, a legenda anuncia: "Cinco páginas sobre as bichas biônicas, e mais uma entrevista com Rogéria, o Zico desta seleção".

No Lampião da Esquina, emprega-se o termo "travesti" no gênero masculino (659 vezes) numa frequência consideravelmente maior que no feminino (9 vezes), o que pode ser explicado pelo entendimento dos lampiônicos, representativo daquele momento histórico, de que as travestis faziam parte de um grande grupo de homossexuais masculinos, pessoas que nasceram com pênis, mas que não costumam se relacionar afetivossexualmente com pessoas que nasceram com vagina. Na maioria das vezes, as identidades travestis, ainda nos dias atuais, não são reconhecidas politicamente, mas vistas com certo receio por parte das bichas. Nos textos do jornal, as diferentes formas de designação do sujeito travesti vão se alterando e isso acontece em meio a outros termos e definições que entram em jogo.

\section{Para além dos artigos feminino e masculino: outros marcadores (in)definidores de travestis}

Bichas, bichas-loucas, bichas-biônicas, mariposas, bonecas, viados, veados, vampiras, damas-da-noite, travestis. Inúmeros termos são utilizados pelo Lampião da Esquina para nomear as nuanças das sexualidades e gêneros desviantes. Muitas vezes em tom pejorativo, podem tornar-se "oásis identitários" em meio a um sistema que vai da visibilidade ao ininteligivel. No entanto, pessoas dissidentes da heteronormatividade (BENTO, 2008, p. 51) formam um grupo nada homogêneo; algumas, inclusive, não desejam quaisquer das opções binárias do construto sexo/gênero e preferem a fluidez, o não-lugar. No levantamento dos conteúdos do jornal, identificamos outros termos que se referem às travestis e/ou à feminilidade exacerbada das bichas (as "quase travestis"). Encontramos 165 ocorrências do termo "boneca", 19 do termo "pintosa", assim como do termo "bicha-louca”, mencionado 19 vezes.

O uso do termo "boneca" está frequentemente associado à passividade, tanto na relação sexual, como na estereotipia do feminino, ou seja, a passividade submissa. Celso Cury, ainda no número zero, afirmou: "Boneca que é boneca, faz 
como eu. Acorda cedo, arruma toda casa, prepara o desjejum do bofe e já põe o almoço no fogo. Lava [...] roupa, dá alpiste para o passarinho e leite para os gatos" (CURY, 1978, p. 8). O trecho transcrito representa o modelo hierárquico de Fry (1982), quando o "ser" feminino da boneca leva à necessidade de tratar o "bofe" como numa relação heterossexual patriarcal.

O termo boneca é utilizado para se referir às travestis ou às bichas (muito) afeminadas. Desconhece-se o surgimento do uso dessa palavra/gíria para designar pessoas em situação de desviados ou transviados. Observamos que o uso do termo tem a ver com a possibilidade de "montar-se". Boneca, enquanto substantivo, define um brinquedo, geralmente de plástico, e que pode ser montado, recriado, do qual se pode trocar a roupa e deixá-la com outra aparência. Como nos informa Benedetti (2005), o termo "montar", ou "montação", é comumente utilizado pela população trans* e diz respeito ao ato de se transformar, por meio de vestimentas, maquiagem, enchimentos, apliques e truques na aparência pessoal, no que se refere ao seu gênero, permitindo assim transitar e performar gêneros diferentes num mesmo corpo (BENEDETTI, 2005, p. 67).

Quanto ao uso da palavra "pintosa", identificamos equivalência com "afeminado", aquele que "dá pinta", que deixa transparecer sua bichice. Nesse aspecto, podemos citar duas referências ilustrativas do processo de alternância de postura sobre essas identidades entre os redatores/autores do jornal. $\mathrm{Na}$ primeira referência, numa das primeiras edições, a efeminação, a "afetação" e o uso dos trejeitos femininos por parte das bichas era sinal de "degradação", considerado impróprio para a construção de uma identidade coletiva positiva. A efeminação "sujava" a imagem, de forma que a bicha pintosa é assim descrita por João Antônio Mascarenhas: “a bicha pintosa é agressiva, agressividade que diga-se de passagem - se compreende, pelas pressões que ela sofre, mas que não se justifica, em meu ponto de vista. Afinal, a velha história; dois erros não fazem um acerto" (MASCARENHAS, 1978, p. 9). A opinião do autor corrobora com a ideia de "sair do gueto" pela emergência de uma "normalidade". A normalidade de um "homem que gosta de outro homem”, mas não a de um homem que se comporta "como mulher". 
Uma segunda referência está atrelada ao surgimento do movimento social organizado, especificamente na figura do grupo soMOS que, assim como o Lampião da Esquina, era majoritariamente formado por homens. Encontramos uma nota publicada no jornal, apoiando o posicionamento do SOMOS, pois existia um discurso "por aí" de que "desmunhecar é decadente" (VIVA 1980, p. 7). Ao discutir sobre a importância da efeminação, da afetação e do dar pinta, o autor do texto salienta:

Acho que as bichas pintosas ou os travestis, ou as lésbicas tipo macho são pessoas corajosas que subvertem o padrão hétero que nos é cobrado a cada instante. Não importa o motivo que leva a isso - se busca de aceitação, ou agressão, identificação com o outro sexo ou com um estereótipo. O que importa realmente é que são pessoas que estão procurando uma expressão mais verdadeira de si próprias e assumir publicamente essa postura é um ato revolucionário de grande importância. (VIVA, 1980, p. 7)

A valorização do "dar pinta", nesse discurso, aponta para um uso político das expressões de gênero, inclusive as consideradas "anormais". O "ato revolucionário" representa o questionamento que as pintosas fazem ao desestabilizar a dicotomia feminino versus masculino, uma desestabilização que borra os discursos de certo e errado quanto ao comportamento e às expressões de gênero.

Já o termo "bicha-louca" possui uma conotação pejorativa. Não foi encontrado defesa do uso do termo como para bonecas e pintosas. Bicha louca aciona a efeminação agressiva, o escândalo. Kulick (2008) faz referência ao escândalo, sendo utilizado por travestis prostitutas de Salvador como estratégia para arrecadar mais dinheiro após um programa ou quando um cliente não pagava - também servia de estratégia de escape quando um furto planejado não se efetivava. Nesse caso, o escândalo servia como arma de proteção das travestis que se prostituem, já que a maioria dos homens que as procuravam preferia fazê-lo de forma sigilosa, muitas vezes por conta de sua condição de homem heterossexual.

Esse "jeito de ser" possibilitava às demais pessoas qualificarem bichas ou travestis como escandalosas, de forma que as bichas se tornavam loucas ao se efeminarem excessivamente (ou masculinizarem-se nos casos das lésbicas), 
confirmando os papéis sociais de gênero que se esperava dos "anormais" e determinando os espaços proibidos e permitidos às identidades não heteronormativas. Nesse sentido, as figuras da travesti, da bicha pintosa, da boneca e da bicha louca, aparecem muitas vezes como desestabilizadoras de uma construção de identidade homossexual masculina "limpa", sem os "trejeitos" que os retirariam da normalidade. É o que faz Luiz Carlos Lacerda escrever:

Quais são esses espaços? O masculino e o feminino. Sem outra opção ou saída, alguns homossexuais, vítimas inconscientes dessa claustrofobia de papéis pré-conceituais passam a "ocupar" os espaços delimitados pelo Sistema seguindo à risca o que manda o figurino. Aí surge a bicha louca e o sapatão (não confundir com os homossexuais assumidos). Cada um deles passa a assumir na vida quotidiana e portanto, inclusive, sexual, os papéis de macho ou fêmea. Ao contrário de deixar fluir dentro da personalidade, harmonicamente, essas duas forças existentes em todo e qualquer ser humano na sua totalidade como pessoa. (LACERDA, 1981, p. 4).

As críticas são feitas às atitudes da bicha-louca como aquela que reproduz o construído e permitido para sua (in)existência, qual seja, o papel da abjeção³, da não normalidade, do não enquadramento, o papel de transviado. Segundo o artigo, o desafio de cada uma das bichas-loucas era buscar o equilíbrio entre "as duas forças" (masculina e feminina) internamente constituídas em cada ser humano.

\section{Entre o "ser" e o "fazer" travesti}

Para além da violência física, exposta em várias reportagens que o próprio jornal apresentava, as travestis sempre sofreram com a violência simbólica da linguagem. Em partes, porque não havia uma organização política dessas reivindicações, e também porque a construção de uma identidade travesti ainda estava iniciando, separando-se da identidade homossexual, embora, no que se apresenta, os jornalistas pouco ouviam do que as travestis tinham a afirmar.

\footnotetext{
3 Abjeção é um conceito inicialmente proposto por Júlia Kristeva, no livro "Power of horror" (1982), mas que Judith Butler (2000; 2016) irá desenvolver e construir a partir de uma lógica ampliada, permitindo discutir os corpos "impensáveis" ou "não inteligíveis" produzidos no interior da matriz discursiva heteronormativa. Um bom exemplo de como o conceito é desenvolvido por Butler, pode ser encontrado no artigo: PRINS, Baukje; COSTERA MEIJER, Irene. Como os corpos se tornam matéria. Estudos Feministas, Florianópolis, v.10, n.1, jan. 2002.
} 
Adão Acosta, autor de um pequeno relato sobre sua participação em alguns "concursos de travestis" em Juiz de Fora, Vitória e Rio de Janeiro, destaca "um detalhe": em todos os concursos, "o primeiro lugar foi sempre para travestis que nada tinham a ver com as bonecas de plástico que atualmente se encontram por aí, cobertas de silicones dos pés à cabeça”. Segundo Acosta, as vencedoras "nos três casos tinham quadris masculinos e rostos tipicamente de homens, embora bem maquilados e bonitos" e aquelas que "se apresentavam com enormes seios" não se destacavam (ACOSTA, 1979, p. 16).

A nota de Acosta gerou a resposta de Bamby de Azevedo, uma travesti leitora que escreveu para o jornal e teve sua carta publicada na seção "Cartas na Mesa”, no número seguinte. Ela afirmava que, ao ler aquele texto, preocupou-se porque

[...] dentro das minorias, nós os travestis somos a menor, e se os homossexuais declararem abertamente a sua antipatia pelos travestis [...] estamos perdidos. [...] Eu acho o preconceito contra os homossexuais uma coisa descabível, mas infelizmente eu sou travesti e sinto isto na carne. (TRAVESTI, 1979, p. 19)

A leitora questiona o autor da reportagem, principalmente por ter afirmado que os "rapazes" vencedores dos concursos não "sonhavam em virar mulher" e não usavam silicone. "Seria crime tentar realizar seus sonhos através do silicone e outras coisas?" - Questiona a leitora. Ela ainda faz afirmações que merecem destaque:

Eu sou travesti apenas porque tenho um pouco de busto à custa de hormônios, tenho o rosto bem feminino e cabelos compridos, mas se você vier a me conhecer verá que sou uma pessoa sensível, inteligente a ponto de, se eu escrevesse esta reportagem, jamais escolheria aquelas frases tão sem necessidade que o senhor escreveu. Lamento que o nosso primeiro contato tenha sido assim, mas eu não estou mais disposta a me calar quando, me pisarem. Beijos, Bamby de Azevedo - São Paulo (TRAVESTI, 1979, p. 19, grifo nosso)

Ao afirmar que é travesti por conta de seus atributos físicos, a leitora sugere que o "ser" travesti estaria mais ligado ao uso de aparatos tecnológicos para alterar o corpo, de maneira "definitiva", diferente de montar-se para um show e "fazer" travesti. Acosta ainda publica uma resposta agradecendo a "cartinha" e destacando que deveria haver algum engano, posto que não tinha 
"falado mal" das travestis que colocavam silicone, mas que apenas tinha alertado para os perigos do silicone líquido, ou seja, desviando o assunto de forma intelectualmente desonesta, pois o silicone líquido sequer havia sido mencionado na reportagem que gerou a carta da leitora. Acosta ainda afirma:

E ainda; existem sérios tipos de rapazes, e os de Juiz de Fora realmente não desejam usar silicone e daí? O resultado que estamos no mesmo barco, ou não? Aliás, detalhe de sua cartinha você diz que é travesti porque usou hormônio, tem rosto feminino e cabelo comprido? Conheço muitos rapazes que têm rosto feminino e cabelos compridos e são machões. Não seria o próprio, homossexual, independente da aparência externa? Pense bem! (TRAVESTI, 1979, p. 19).

Essa polêmica corrobora o entendimento de que a divisão entre o "ser" e o "fazer" travesti reside no corpo. É no corpo que as travestis "se tornam". Essas afirmações encontradas nos textos-vestígios funcionam como fragmentos, palimpsestos do que mais tarde veríamos ser a construção da identidade travesti. A travestilidade vai se constituindo ao longo dos anos posteriores, em especial na década de 1980, através dos e pelos discursos sobre o corpo. As questões corporais da identidade travesti foram debatidas, muito posteriormente, através de etnografias, tais como a de Kulick (2008) e Benedetti (2005). Para o último, inclusive, trata-se do fio condutor de toda a análise. Com expressões como "toda feita”, que dá título ao livro (BENEDETTI, 2005), a discussão tem como foco principal a questão de como o corpo da travesti é concebido, feito, criado e moldado em nome de um feminino ideal. Outro autor que aborda a temática é Tiago Duque (2013), ampliando a discussão e fazendo refletir sobre a passabilidade dos corpos. A passabilidade como conceito define o ato de "passar por”, no caso das travestis, passar por mulher, seja por meio da montação ou do uso de tecnologias de mudança corporal, acessadas por meio dos hormônios, do uso do silicone (industrial ou prótese) e ainda por meio de cirurgias plásticas.

As definições de "travesti de show" dão indicações do quanto essas identidades, nesse período, ainda circulavam sem fixidez. Aqui, duas identidades parecem conviver em um "guarda-chuva" travesti: de um lado, uma mais próxima do "ser" travesti o tempo todo, com o corpo modificado e a "batalha" como profissão; de outro, um "fazer" travesti na montação e num lugar específico, o 
palco. Poder-se-ia ser travesti, mas também fazer travesti, ainda que todas fossem, nos discursos correntes na época, homossexuais em uma escala de feminilidade.

Esse embate entre o "ser" e o "fazer", tendo como enfoque o corpo, sua montação e/ou transformação, permeia a maioria das matérias sobre travestis do Lampião da Esquina. Darcy Penteado redigiu uma matéria em que descreveu sua ida a Portugal, contando sobre o momento de redemocratização no que se referia aos homossexuais portugueses (PENTEADO, 1979, p. 3). Penteado conta que os shows de travestis teriam sido ótimos, em especial por razão de um "primitivismo" na performance, comparando com os rapazes que "faziam travesti” no eixo Rio de Janeiro-São Paulo, que não modificavam seus corpos, mas se usavam apenas da montação. Ao fazer essa observação, reflete sobre "o exagero dos travestis de shows de São Paulo e Rio atualmente, na base de plásticas, silicone e hormônios", fato que levava os shows de travestis e os shows de vedetes da televisão, muito famosas pela mesma época, a figurarem numa mesma posição, diferenciando-se somente na "importação mental do espectador" (PENTEADO, 1979, p. 3).

A discussão sobre o termo travesti pertencer ou não ao espectro da homossexualidade aparentemente faz parte de toda a construção identitária da homossexualidade nas décadas de 1970 e 1980. No jornal, isso se faz presente em todas as publicações sobre o assunto. Nas últimas edições, porém, observamos uma maior discussão acerca da travestilidade como uma identidade em separado, na perspectiva do que se entende por "ser" travesti.

\section{Ecos dos discursos sobre as travestis}

Os discursos sobre as identidades travestis no jornal Lampião da Esquina não eram homogêneos, embora seja preciso reconhecer que, ainda hoje, tenhamos uma identidade política de pessoas que se autoafirmam travestis, como heterogênea. Entretanto, o jornal contribuiu para colocar em pauta as discussões sobre essas identidades e se, de um lado, reforçou certos estereótipos, de outro, trouxe à cena pública a heterogeneidade do grupo 
conhecido como homossexual, num momento em que no Brasil essas afirmações tornavam-se atos políticos.

Câmara (2002), ao analisar os discursos proferidos por João Antônio Mascarenhas (ex-lampiônico) na Assembleia Nacional Constituinte, em 20 de maio e 24 de junho de 1987, identifica um esforço para diferenciar a travesti do homossexual. Segundo o autor, Mascarenhas afirmava que havia na sociedade uma confusão entre o homossexual e o travesti [sic], e que "para o movimento gay [sic] era muito ruim". Assim, para Mascarenhas, "há o homossexual comum e há o travesti, que em muitos casos são prostitutos e acabam se envolvendo com pequenos furtos ou drogas", de forma que a "imagem predominantemente atribuída ao homossexual na verdade corresponderia ao travesti e esta aproximação atrapalharia o movimento organizado" (CÂMARA, 2002, p. 57).

A escolha pela afirmação da identidade homossexual como normalizada/aceita precisou ser higienizada nos moldes heteronormativos, muitas vezes custando a rejeição de outras possibilidades identitárias. Outra questão importante a ser observada diz respeito ao uso dos termos "travesti", "transexual" ou "transgênero", como ocorre em outros países, a exemplo dos EUA. Uma das primeiras conquistas do movimento social de travestis e transexuais da década de 1990 foi a inclusão do "T" na sigla do movimento de “lésbicas e gays”. Em 1995, no VIII Encontro Brasileiro de Gays e Lésbicas (EBGL), conseguiu-se a aprovação da inclusão da identidade travesti; o próximo encontro passou a se denominar Encontro Brasileiro de Gays, Lésbicas e Travestis (EBGLT) (FACCHINI, 2005).

Em 1997, no V Encontro Nacional de Travestis, Transexuais e Liberados sobre a AIDS (ENTLAIDS), em São Paulo, os conflitos por identidades "T" se acentuam. Há uma disputa entre o uso da letra referindo-se a travestis ou transexuais. Camile Cabral, militante estrangeira participante do evento, defendia o uso do termo "transexual" como um aglutinador, sendo que as travestis deveriam se inserir nessa categoria. Todavia, as travestis resistem e mantêm-se enquanto identidade, não aceitando e não se sentindo representadas pelo termo “transexual” (CARVALHO; CARRARA, 2013). 
Outro termo que os movimentos internacionais, em especial os europeus e os estadunidenses, passaram a usar estrategicamente como aglutinador de todas as pessoas que transitam ou alteram seu gênero foi "transgênero", em inglês transgender. Não houve adesão ao termo no Brasil, em se tratando das travestis, e a disputa seguiu nos anos seguintes, por exemplo, em 2004, no II Encontro Paulista GLBT. Os/as organizadores/as passaram a usar o termo transgênero nas suas falas na intenção de aglutinar as identidades, mas cada vez que se "ouvia a palavra transgênero as participantes travestis e transexuais simulavam um espirro" (CARVALHO; CARRARA, 2013, p. 19).

Com a afirmação de que transgênero era um conceito e não uma identidade, as travestis mantiveram-se marcadas como diferentes das transexuais nas siglas dos movimentos. Outros fatores contribuíram para o não uso do termo; um deles foi a própria sonoridade da palavra, que facilmente se confundia com "transgênico", fruto da discussão corrente, no início dos anos 2000, acerca dos alimentos modificados geneticamente. Deve-se também considerar que, no Brasil, travestis e transexuais não se sentiam contempladas com o termo que também define aquelas pessoas que transitam entre os gêneros (CARVALHO; CARRARA, 2013, p. 21).

Ao que se observa, o "fazer" travesti foi sendo substituído por outras definições e o termo transgênero foi caindo em certo desuso, até reaparecer nas discussões de gênero da década de 2010. Em especial, mais recentemente, com a ativista e pesquisadora Letícia Lanz, através de seu livro O corpo da roupa: introdução aos estudos transgêneros, lançado em 2015.

\section{Breves considerações finais}

Findada essa análise, mas não esgotando o assunto, uma vez que ainda precisamos pesquisar muito mais para entender minimamente a construção das identidades LGBTI no Brasil e, nesse caso, das travestis, observamos que o uso do termo "travesti" e a construção dessas identidades atravessaram as últimas décadas, ramificando-se numa maior quantidade de definições. 
Nesse processo, o Lampião da Esquina teve um importante papel na medida que, em seu esforço discursivo para definir o ser travesti, problematizou a sua existência evidenciando uma condição de "abjeção", ou "corpo impensável”, “ininteligível”. O discurso do jornal constituía-se em um ato político, na medida em que a maioria dos escritos procurou inserir o grupo dos homossexuais (categoria que integrava travestis) numa normalidade heteronormativa que condenava a efeminização e não aceitava um corpo biologicamente masculino apresentado como mulher, evidenciando assim, a permanência, no período analisado, do discurso que associa sexo biológico ao gênero.

Nos anos subsequentes, enquanto o "ser" travesti separou-se dos discursos médicos e das ciências psi dos diagnósticos de travestismo (sic) e do transexualismo ( $\mathrm{sic}$ ), tornando-se uma identidade político-social, o "fazer" travesti transformou-se em outras possibilidades, como o transformismo e a performance. Em algumas situações, em especial após os anos 2000, houve uma assimilação da cultura LGBT estadunidense, com o uso de termos como, por exemplo, cross-dressere drag queen. O primeiro termo (cross-dresser) descreve pessoas possuidoras de pênis que preferem apresentar sua expressão de gênero, principalmente (mas não exclusivamente), em situações de realização de desejos sexuais, como femininas, mesmo mantendo-se e identificando-se como homens cotidianamente, independente da orientação sexual. O segundo (drag queen) denomina qualquer pessoa que se utiliza do artifício da montação e da performance para expressar, momentaneamente, aspectos femininos (a versão com performance masculina existe e chama-se Drag King), com intenção de apresentação artístico-cultural ou no uso de humor.

Essas divisões e mudanças naquilo que identificam as identidades travestis, são parte de um processo dialógico que se estabelece entre a luta política das envolvidas, e do surgimento de novas teorias acadêmicas que ajudam a fundamentar e compreender, mas também servem para amparar novas lutas políticas. 


\section{Referências}

ACOSTA, Adão. Bom mesmo é carne de homem. Lampião da Esquina, Rio de Janeiro, ano 2, n. 17, p. 9, outubro, 1979.

AMARAL, Marília dos Santos; SILVA, Talita Caetano; CRUZ, Karla de Oliveira e TONELI, Maria Juracy Filgueiras. "Do travestismo às travestilidades": uma revisão do discurso acadêmico no Brasil entre 2001-2010, Psicologia \& Sociedade (online), v. 26, n. 2, p. 301-311, 2004.

BARDIN, Lawrence. Análise de conteúdo. Lisboa: Edições 70, 1977.

BELMONTE, Pilar. História da homossexualidade: ciência e contra-ciência no Rio de Janeiro (1970-2000). 2009. Tese (Doutorado em História das Ciências e da Saúde) -Fundação Oswaldo Cruz. Casa de Oswaldo Cruz, Rio de Janeiro, 2009.

BENEDETTI, Marcos. Toda feita: o corpo e o gênero das travestis. Rio de Janeiro: Garamond, 2005.

BENTO, Berenice. Apresentação. In: PELÚCIO, Larissa. Abjeção e desejo: uma etnografia travesti sobre o modelo preventivo de aids. São Paulo: Annablumme: FAPESP, 2009.

BENTO, Berenice. O que é transexualidade. São Paulo: Brasiliense, 2008.

BÖER, Alexandre (org.). Construindo a igualdade: a história da prostituição de travestis em Porto Alegre. Porto Alegre: Igualdade: 2003.

BUTLER, Judith. Problemas de Gênero: feminismo e subversão da identidade. Tradução de Renato Aguiar. 11. ed. Rio de Janeiro: Civilização Brasileira, 2016.

BUTLER, Judith. Corpos que pesam: sobre os limites discursivos do sexo. Tradução de Tomaz Tadeu da Silva. In: LOURO, Guacira (org.). O corpo educado: pedagogias da sexualidade. 2. ed. Belo Horizonte: Autêntica, 2000. p.151-172.

CADENGUE, Rogério Bastos. A comunicação em comunidades homossexuais. In: MELO, José Marques de; EPSTEIN, Isaac; FRANCO, Maria Sylvia Carvalho (orgs.). Comunicação e classes subalternas. São Paulo: Cortez, 1980. p.186-197.

CÂMARA, Cristina. Cidadania e orientação sexual: a trajetória do grupo Triângulo Rosa. Rio de Janeiro: Academia Avançada, 2002.

CARDOZO, Fernanda. Parentesco e parentalidades de travestis em Florianópolis. Florianópolis: NIGS, n.1, v.1, 2010.

CARVALHO, Mario; CARRARA, Sérgio. Em direito a um futuro trans? contribuição para a história do movimento de travestis e transexuais no Brasil.

Sexualidad, Salud y Sociedad, Rio de Janeiro, n. 14, ago. 2013. 
CURY, Celso. Coluna do Meio. Lampião da Esquina, Rio de Janeiro, edição experimental, n. 0, p. 8, abril, 1978.

DUQUE, Tiago. Gêneros incríveis: identificação, diferenciação e reconhecimento no ato de passar por. 2013. Tese (Doutorado em Ciências Sociais) Universidade Estadual de Campinas, Campinas, 2013.

DUQUE, Tiago. Montagens e desmontagens: vergonha, estigma e desejo na construção das travestilidades na adolescência. Dissertação (Mestrado em Ciências Humanas). - Programa de Pós-Graduação em Sociologia, Universidade Federal de São Carlos, São Carlos, 2009.

FACCHINI, Regina. Sopa de letrinhas? movimento homossexual e produção de identidades coletivas nos anos 1990. Rio de Janeiro: Garamond, 2005.

FOUCAULT, Michel. História da sexualidade 1: a vontade de saber. Tradução de Maria Thereza da Costa Albuquerque. 17. ed. Rio de Janeiro: Edições Graal, 2006.

FRY, Peter. Para inglês ver: identidade e política na cultura brasileira. Rio de Janeiro: Zahar, 1982.

GAY-MACHO: uma nova tragédia americana? Lampião da Esquina, Rio de Janeiro, ano 1, n. 8, p. 8, janeiro, 1979.

GREEN, James Naylor. "Mais amor e mais tesão": a construção de um movimento brasileiro de gays, lésbicas e travestis. Cadernos Pagu, Campinas, n. 15, p. 271-295, 2000.

GRUPO Somos: uma experiência. Lampião da Esquina, Rio de Janeiro, ano 1, n. 12, p. 2, maio, 1979.

HOUAISS, Antônio. Minidicionário Houaiss da Língua Portuguesa. 3. ed. rev. e ampl. Rio de Janeiro: Objetiva, 2008.

KUCINSKI, Bernardo. Jornalistas e revolucionários: nos tempos da imprensa alternativa. 2. ed. rev. e ampl. São Paulo: EDUSP, 2001.

KULICK, Don. Travesti: prostituição, sexo, gênero e cultura no Brasil. Tradução de Cesar Gordon. Rio de Janeiro, Editora Fiocruz, 2008.

LACERDA, Luiz Carlos. Vítimas da falta de espaço. Lampião da Esquina, Rio de Janeiro, ano 3, n.32, p. 4, janeiro, 1981.

LANZ, Letícia. O corpo da roupa: a pessoa transgênera entre a conformidade e a transgressão das normas de gênero. Uma introdução aos estudos transgêneros. Curitiba: Transgente, 2015.

LAQUEUR, Thomas. Inventando o sexo: corpo e gênero dos gregos até Freud. Tradução de Vera Whately. Rio de Janeiro: Relume Dumará, 2001. 
LEITE JÚNIOR, Jorge. Nossos corpos também mudam: sexo, gênero e a invenção das categorias "travesti" e "transexual" no discurso médico científico. 2008. Tese (Doutorado em Ciências Sociais) - Pontifícia Universidade Católica, São Paulo, 2008.

LIMA, Aline Soares. Quem sou eu: autorrepresentações de travestis no Orkut. 2009. Dissertação (Mestrado em Arte e Cultura Visual). - Programa de PósGraduação em Cultura e Artes, Universidade Federal de Goiás, 2009.

MACRAE, Edward. A construção da igualdade: identidade sexual e política no Brasil da "abertura". Campinas: UNICAMP, 1990.

MASCARENHAS, João Antônio. Sobre tigres de papel. Lampião da Esquina, Rio de Janeiro, ano 1, n. 4, p. 9, 25 de agosto a 25 de setembro, 1978.

NOGUEIRA, Francisco Jander de Souza. A saga da beleza: corpo e travestilidade em Fortaleza - CE. 2009. Dissertação (Mestrado em Sociologia) - Programa de Pós-Graduação em Sociologia, Universidade Federal de Pernambuco, Recife, 2009.

PATRÍCIO, Maria Cecília. No truque: transnacionalidade e distinção entre travestis brasileiras. 2008. Tese (Doutorado em Antropologia). - Programa de Pós-Graduação em Antropologia, Universidade Federal de Pernambuco, Recife, 2008.

PELÚCIO, Larissa. Na noite nem todos os gatos são pardos: notas sobre a prostituição travesti. Cadernos Pagu, Campinas, v. 25, p. 217-248, 2005.

PENTEADO, Darcy. A louca da Consolação. Lampião da Esquina, Rio de Janeiro, ano 3, n. 27, p. 16, agosto, 1980.

PENTEADO, Darcy. "Ma che cosa é questa?”. Lampião da Esquina, Rio de Janeiro, ano 1, n. 9, p. 6, fevereiro, 1979.

PENTEADO, Darcy. O travesti, esse desconhecido. Lampião da Esquina, Rio de Janeiro, ano 2, n. 23, p. 3, abril, 1980.

PENTEADO, Darcy. PORTUGAL: sem bacalhau, mas com muito paneleiro. Lampião da Esquina, Rio de Janeiro, ano 2, n. 13, p. 3, junho, 1979.

PRINS, Baukje; COSTERA MEIJER, Irene. Como os corpos se tornam matéria. Estudos Feministas, Florianópolis, v.10, n.1, jan. 2002.

RODRIGUES, Rita de Cássia Colaço. De Daniele a Chrysóstomo: quando travestis, bonecas e homossexuais entram em cena. 2012. Tese (Doutorado em História Social) - Universidade Federal Fluminense, Niterói, 2012. 
SAINDO do Gueto. Lampião da Esquina, Rio de Janeiro, edição experimental, número 0, p. 2, abril, 1978.

SENHORES do Conselho. Lampião da Esquina, Rio de Janeiro, edição experimental, número 0, p. 2, abril, 1978.

SILVA, Aguinaldo. As palavras, para que teme-las?, Lampião da Esquina, ano 1, n. 3, p. 5, 25 de julho a 25 de agosto, 1978.

SILVA, Aguinaldo. Síndico quer Verushka usando gravata e paletó. Lampião da Esquina, ano 1, n. 10, p. 3, março, 1979.

SILVA, Andréia Cristina Lopes Frazão da. Implicações metodológicas da aplicação da categoria gênero de matriz pós-modernista em estudos históricos. In: ANDRADE, Marta Mega de; SEDREZ, Lise Fernanda; MARTINS, William de Souza (orgs.). Corpo: sujeito e objeto. Rio de Janeiro: Ponteio, 2012. p. 61-80.

SILVA, Hélio R. S. Travestis: entre o espelho e a rua. Rio de Janeiro: Rocco, 2007.

SIMÕES, Júlio Assis; FACCHINI, Regina. Na trilha sonora do arco-íris: do movimento homossexual ao LGBT. São Paulo: Editora Fundação Perseu Abramo, 2009. (Coleção História do Povo Brasileiro).

TRAVESTI protesta. Lampião da Esquina, Rio de Janeiro, ano 2, n. 18, p. 19, novembro, 1979.

VIVA a pintosa! Lampião da Esquina, Rio de Janeiro, ano 3, n. 26, p. 7, julho, 1980. 